\title{
FUNCTIONS OF STIMULUS AND RESPONSE IN PAIRED-ASSOCIATE VERBAL LEARNING
}

\author{
YASUO MORIKAWA
}

\author{
Kyoto University
}

Since Calkins $(3,4)$ and Jost (19) of 1890 s, a large number of experiments in paired-associate learning on verbal material have been performed, using various kinds of methods and dimensions of material, as one of the most intensive research fields in experimental psychology. A number of systematic theories have been proposed concerning specific phenomena in the field of verbal learning, such as Ir-theory on the distribution of practice and reminiscence, two-factor theory on retroactive inhibition, etc., but Gibson's stimulus differentiation theory is the only general theory of paired-associate learning which can be experimentally tested.

This paper will be concerned with basic mechanisms of $S$ and $R$ in paired-associates, and with the investigation of some functions which relate to backward learning of paired-associate verbal materials. First, we will review variables affecting paired-associate learning, next will attempt to analyze the process of its formation. Our discussion will begin with a critique of Gibson's theory, and then will develop into hypotheses based upon an integration of the results which have been obtained in studies on paired-associate learning in America and in Japan.

\section{Vartables in Paired-Assoctate Learning}

1. Contradiction on the relative importance of $S$ and $R$

According to Gibson's theory, "a major necessity of verbal learning is the establishment of discrimination among the items to be learned, and that this process of discriminating is actually a fundamental part of what is called generally the learning process" $(9$, p. 197). She did not delineate the role of the response in her hypothesis, and mentioned that "it is conceivable that something analogous to generalization of stimulus items might occur among response items, especially since every response is in a sense a stimulus as well"' $(9$, p. 201). Then, she demonstrated that the role of $\mathrm{R}$ items is inferior to $\mathrm{S}$ items by referring to Thorndike (67), and McGeoch \& McGeoch (33). Indeed, later studies $(7,10,77,78,79)$ had also confirmed the importance of $\mathrm{S}$ factor over $\mathrm{R}$ factor in intralist generalization.

On the other hand, in 1937, Kuraishi (27) found that it is easier to recall well-organized material from weakly organized one than to recall in the reversed direction. Umemoto (71) inquired into the phenomenon and found that the difficulty of learning, in terms of number of recalled items after several presentations and number of trials to a criterion by the paired anticipation method, depends more on the difficulty of $\mathrm{R}$ material than that of $\mathrm{S}$ materialitems were alphabets, nonsense syllables, or meaningful words-, and concluded that "the effect of $\mathrm{R}$ items was greater than that of $\mathrm{S}$ items." After that, these results were confirmed by Morikawa (35).*

Recently, in America some investigators $(34,54,55,76,82,83)$ began to notice the importance of response factors in transfer or retroaction experiments. Based upon these results, Mandler (29) postulated a number of assumptions on response factors in human learning. Recent studies concerning meaningfulness $(5,21,30,65)$ have indicated that in learning meaningfulness of $R$ items was equal to or more important than that of $S$ items. Noble \& McNeely also suggested that $\mathrm{S}-\mathrm{R}$ motor-pattern hypothesis that "differential facilitation is primarily connected with responding (articulation) and that stimulus factors are of secondary importan-

\footnotetext{
* A detailed historical review on this topic is shown in Umemoto's paper (73).
} 
ce" (53, p. 21.). Thus, these studies presented a serious, critical argument against Gibson's view.

However, from these apparently conflicting results, we might deduce the hypothesis which would explore the mechanism of the formation of paired-associate learning.

2. Learning as a function of intralist similarity among $S$ items

Underwood and his collaborators $(7,77,78,79)$ studied on the rate of learning of a list varying in the degree of intralist $\mathrm{S}$ similarity and/or $\mathrm{R}$ similarity, and showed that variation of similarity among $S$ items was more effective than that among $R$ items, when number of trials to a criterion of one errorless trial was used as measure. It is supposed that paired-associate learning is a function of intralist S similarity. Only one of their studies (7) showed that the rate of learning was a function of intralist $\mathrm{R}$ similarity.

Morikawa (46) also investigated the effect of intralist similarity on learning. In Experiment I, which used 6 pairs of nonsense syllables (mean association-value was $17.7(70)$ ), there were 3 conditions that varied in the degree of intralist phonetic similarity, i.e. H-L, L-H, and L-L ( $\mathrm{H}$ means intralist high similarity, L means intralist low similarity). The paired-anticipation method was used, and the presentation rate was $2 \mathrm{sec}$. for $\mathrm{S}$ and $2 \mathrm{sec}$. for $\mathrm{S}-\mathrm{R}$ pair. Intertrial interval was $2 \mathrm{sec}$. Three different orders of the pairs were used to minimize the possibilities of serial learning. Learning criterion was 3 successive errorless trials. Subjects were 9 university students ( 6 experienced, 3 naive to verbal learning experiments), who served under all conditions according to counterbalanced orders. Experiment II was the same as Experiment I, except that lists consisted of 9 pairs of adjectives, and that 12 experienced university students were used. Similarity was varied on the semantic dimension. Each items in lists was selected from Umemoto and other's (75) list. Learning curves as a function of intralist similarity in both experiments are

Table 1 Summary of Analyses of Variance of Trials to One Perfect Trial in Two Experiments on Intralist Similarity (46), and t's between Paired Means.

\begin{tabular}{|c|c|c|c|c|}
\hline & \multicolumn{2}{|c|}{$\begin{array}{l}\text { N Phonetic } \\
\text { Similarity }\end{array}$} & \multicolumn{2}{|c|}{$\begin{array}{l}\text { M Semantic } \\
\text { Similarity }+ \text { t }\end{array}$} \\
\hline Source & df & $F$ & df & $\mathrm{F}$ \\
\hline Similarity & 2 & $4.69 *$ & 2 & $28.34 \star \star$ \\
\hline Order & 2 & $5.46^{\star}$ & 2 & 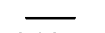 \\
\hline List set & & & 1 & 3.16 \\
\hline Subjects & 8 & 3.30 & 10 & $6.81^{\star \star}$ \\
\hline Error & 14 & $(55.59) \dagger$ & 20 & $(0.35) \dagger$ \\
\hline t-test & & $t$ & & $t$ \\
\hline $\mathrm{H}-\mathrm{L}: \mathrm{L}-\mathrm{L}$ & & $2.95^{\star}$ & & $7.61 \star \star$ \\
\hline L-H:L-L & & 0.73 & & $3.22 \star \star$ \\
\hline $\mathrm{H}-\mathrm{L}: \mathrm{L}-\mathrm{H}$ & & $2.22 \star$ & & $4.39 * \star$ \\
\hline$\star \mathrm{p}<.05$ & $\star \star$ & & & \\
\hline$\dagger$ Values & & icate $\mathrm{M}$ & es. & \\
\hline tt Square & $f \circ$ & & hes & \\
\hline
\end{tabular}
shown in Figs. 1 and 2. Analyses of variance of trials to one perfect trial are summarized in Table 1. It will be clear that the rate of learning depends mainly on similarity of intra-S.

3. Learning as a function of familiarity of $R$ items

Japanese studies $(27,35,71)$ which have shown that $R$ factor was more important than $S$, against the results of Gibson and Underwood, have used meaningfulness dimension as variable of material to be learned. American studies (5, 21, 30, 53, 65) which investigated the effect of meaningfulness on the rate of paired-associate learning also confirmed that meaningfulness of $\mathbf{R}$ side was more important. However, Mandler \& Campbell (30) obtained the results that variation of $\mathrm{S}$ was equally effective on the rate of learning. 


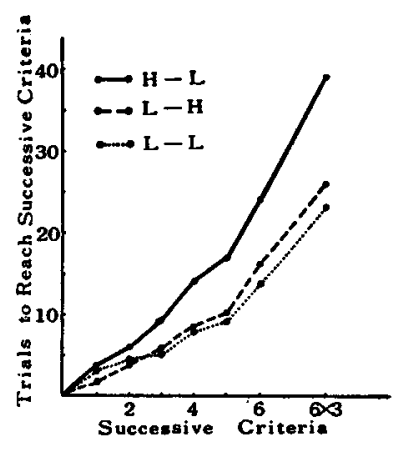

Fig. 1 Learning curves under 3 conditions of intralist phonetic similarity in paired nonsense syllable lists (46, Exp. 1).

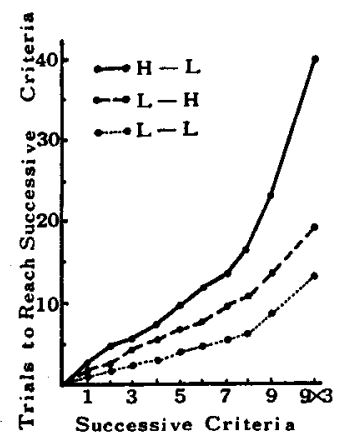

Fig. 2 Learning curves under 3 conditions of intralist semantic similarity in paired adjective lists (46. Exp. II).

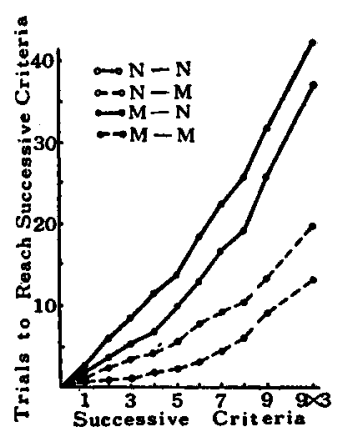

Fig. 3 Learning curves under 4 conditions of meaningfulness of $S$ and/ or R (45, Exp. I).

Morikawa (45) performed an experiment that examined the influence of meaningfulness on $S$ and $R$. Each list, in which intralist similarity was minimized, consisting of 9 pairs of N-N, $\mathrm{N}-\mathrm{M}, \mathrm{M}-\mathrm{N}$, or $\mathrm{M}-\mathrm{M}$ (N means nonsense syllables, and the mean association-value of a list was about $20 \%$ each (70). M means two-syllable familiar words), was learned by the paired-anticipation method to a criterion of 3 successive errorless trials. Otherwise procedures were the same as in the previous experiments (46). Subjects were 8 naive university students, who participated in all conditions by the use of Latin squares. Learning curves under these four conditions are shown in Fig. 3. Analysis of variance was used, based on the number of trials to one perfect trial (Table 3). Two list having $N$ in $R$ side (N-N and $M-N)$ required far more trials than two lists having $M$ in $R$ side (N-M and $M-M$ ). However, the difference in $N$ and $\mathrm{M}$ in $\mathrm{S}$ side did not affect the rate of learning. $\mathrm{S} \times \mathrm{R}$ interaction was also not significant. Clearly, these results agreed with the previous finding that the effect of meaningfulness on learning depended mainly upon the kind of $\mathrm{R}$ material.

Variation in meaningfulness, however, is inevitably accompanied by variation in familiarity. Usually, meaningful words are familiar, while nonsense syllables are unfamiliar. As can be seen by several studies $(28,50,68,84)$, the frequency of usage of words (familiarity) has a high correlation with their meaningfulness. Therefore, the above results may be due to a factor concerning familiarity.

But, familiarity may be treated independently of meaningfulness, that is, the degree of familiarity of nonsense syllables can be experimentally increased without increasing the degree of meaningfulness, by the procedure of pre-differentiation or familiarization $(8,16,52)$. Sheffield (65) found that learning was easier when $\mathrm{R}$ items were familiarized than when $\mathrm{S}$ items were familiarized. Hovland \& Kurtz (16) and Noble (52) found that the rate of serial rotelearning was a function of the degree of prelearning syllable familiarization.

Now, the writer presents the data to determine which of the two factor (meaningfulness

* But, according to Noble (51) familiarity and frequency are logically separable components, though both are highly correlated. The one is psychological, the other physical. 
and familiarity) is more important as a variable of $\mathrm{R}$ in paired-associate learning. One of Haraguchi's experiments (14) was related to this issue. Sixteen university students (8 experienced and 8 naive) were asked to learn a list of 9 pairs to one perfect trial under 4 list conditions, i.e. $\mathrm{N}-\mathrm{N}, \mathrm{N}-\mathrm{M}, \mathrm{M}-\mathrm{N}$, and $\mathrm{M}-\mathrm{M}$. The non-association values of $\mathrm{M}$ items in a list were $0-4$, those of $\mathrm{N}$ items were $60-69$ (74). Other procedures were the same as in Morikawa's experiment on meaningfulness (45). Table 2 shows the number of trials to learn and the differences between $\mathrm{N}$ and $\mathrm{M}$ each for $\mathrm{S}$ and $\mathrm{R}$. The differences shown between the two differences $\mathbf{N}$ and $M$ with respect to $R$, and between $N$ and $M$ with respect to $S$ were greater for the naive subject than for the experienced. Introspection did not reveal that the experienced subject added meaning to $\mathrm{N}$ items nor any such procedure was done before the main experiment. Thus the results may be due to the fact that

Table 2 Mean Number of Trials to One Perfect Learning under 4 Conditionsof Meaningfulness for Experienced and for Naive Subjects (From Haraguchi's Exp.III (14)).

\begin{tabular}{|c|c|c|c|c|c|}
\hline & \multirow{2}{*}{\multicolumn{2}{|c|}{$\begin{array}{l}\text { Experienced group } \\
(\mathrm{N}=8) \\
\mathrm{S} \text { conditions }\end{array}$}} & \multicolumn{2}{|c|}{$\begin{array}{c}\text { Naive group } \\
(\mathrm{N}=8)\end{array}$} \\
\hline & & & & $\mathrm{S}$ con & ditions \\
\hline & & $\mathbf{N} \quad \mathbf{M}$ & $\begin{array}{l}\text { Diff. Mean } \\
\text { diff. }\end{array}$ & $\begin{array}{ll}\mathbf{N} & \mathbf{M} \\
\end{array}$ & $\begin{array}{l}\text { Diff. Mean } \\
\text { diff. }\end{array}$ \\
\hline & $N$ & $\begin{array}{ll}12.1 & 7.1 \\
\end{array}$ & 5.0 & 32.021 .4 & 10.6 \\
\hline$K$ & $M$ & 6.9 & 28 & 16.611 .0 & 5.6 \\
\hline $\begin{array}{l}\text { condi- } \\
\text { ionts }\end{array}$ & $\begin{array}{l}\text { Diff. } \\
\text { Mean } \\
\text { diff. }\end{array}$ & $\begin{array}{c}5.2 \\
4.1^{3.0}\end{array}$ & & $\begin{array}{c}15.410 .4 \\
12.9\end{array}$ & \\
\hline
\end{tabular}
either the experienced had familiarized $\mathrm{N}$, or they had learned how-to-learn- $\mathrm{N}$.

We will show two experiments which investigate the effect of familiarization of $S$ and/ or R. Experiment II in Morikawa's third study (45) consisted of two phases, the familiarization phase and the transfer learning phase. For the familiarization phase, a list of 9 or 18 pairs consisting of components of $\mathrm{N}$ (the mean association value of a list was about $20 \%$ each (70)) was learned up to two successive errorless trials (for the 9 pairs) or one errorless trial (for 18 pairs) by the paired-anticipation method. One minute later, the paired letters were used as

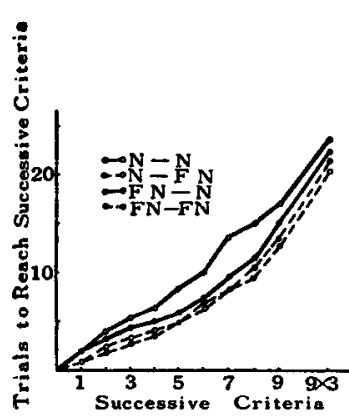

Fig. 4 Learning curves under 4 conditions of familiarity of $S$ and/or R (45, Exp. II).
Table 3 Summary of Analyses of Variance of Trails to One Perfect Trial in Two Experiments on Meaningfulness and Familiarity (45).

\begin{tabular}{|c|c|c|c|c|}
\hline & \multicolumn{2}{|c|}{ Meaningfulness } & \multicolumn{2}{|c|}{ Familiarity } \\
\hline Source & $\mathrm{df}$ & F & $\mathrm{df}$ & $\mathrm{F}$ \\
\hline S condition & 1 & 4.3 & 1 & $=$ \\
\hline $\mathrm{R}$ condition & 1 & $56.1^{\star \star}$ & 1 & $6.00 *$ \\
\hline$S \times R$ & 1 & & 1 & 1.59 \\
\hline Order & 3 & 1.3 & 3 & 1.80 \\
\hline Lists & & & 3 & 1.57 \\
\hline Subjects & 7 & $3.5^{\star}$ & 7 & \\
\hline Error & 18 & $(4.3)$ & 15 & (15.78) \\
\hline
\end{tabular}

$\star \mathrm{p}<.05 \quad \star \star \mathrm{p}<.01$

Values in parenthesis indicate Mean Squares.

familiarized $\mathrm{N}$ (FN) in the transfer lists. In transfer phase the usual paired-associate learning was used with the following 4 list-designs: N-N, N-FN, FN-N, and FN-FN of 9 pairs each. The other procedures in this phase were the same as in the previous studies $(45,46)$. Eight university students who had experienced few verbal learning experiments served as subjects under all conditions according to Latin squares. The results are shown in Fig. 4. The number 
of trials to one perfect trial was greater when $\mathrm{R}$ items were unfamiliar $\mathrm{N}$ than when they were familiar N (FN), and this was independent of $S$ familiarization. Another experiment (45) that used somewhat different procedures of familiarization and transfer learning also confirmed these findings. The results, therefore, support the hypothesis that learning is a function of familiarity of $\mathrm{R}$ items rather than that of meaningfulness of $\mathrm{R}$ items.

4. $S-R$ associative strength as a function of meaningfulness of $S$ items and/or $R$ items

In the previous section, we suggested that the reason why learning was easier when $R$ was $M$, may not be its meaningfulness but its familiarity. Then, what is the role of meaningfulness in paired-associate learning? Several investigators $(21,31,53)$ confirmed that learning was a function of meaningfulness, when meaningfulness of $S$ and $R$ were varied together. However, these works could not determine whether it was due to $S-R$ connection factor or to $\mathrm{R}$ factor alone.

The experiments on familiarity were compared with the experiment on meaningfulness. Analyses of variance based on both experiments were summarized in Table 3. Generally, influence of familiarity was not so large as that of meaningfulness, though for both variables influence of $R$ variations was greater than that of $S$ variations. First, the differ ence in the degree of familiarity should be considered. Familiar meaningful words ( $M$ ) should be much more familiar as compared with experimentally induced familiarization (FN). Secondly it is suggested that the unique characteristic of mediation, which only $\mathrm{M}$ has, may cause such differences.

It is natural that meaningfulness should facilitate and strengthen the connection between $\mathrm{S}$ and $\mathrm{R}$, because of mediating function which is the property of meaning. Its directive evidence was obtained in investigating retention of paired-associates $(27,40)$. Here the data suggesting this effect are presented in Fig.10 (its procedures are mentioned later), in which forward recall was in order of the easiness $\mathrm{M}-\mathrm{M}>\mathrm{M}-\mathrm{N} \quad \mathrm{N}-\mathrm{M}>\mathrm{N}-\mathrm{N}$ after learning to criteria of 6/9 correct responses on a single trial and one errorless trial (45).

Interaction among the three dimensions of materials mentioned above has been investigated using various experimental design $(14,30,37,40,62,72)$. There are some other dimensions of materials as variables in paired-associate learning; for example, organization other than meaning, S-R homogeneity, S-R compatibility, etc. $(22,27,49,56,63,71)$. Although they were important factors in paired-associate learning, they were not mentioned in this paper for want of space.

\section{5. $S$-R-trials surfaces}

In Fig. 5 was drawn the number of trials to one perfect trial as a function of similarity and familiarity of $S$ and $R$. In the left two figures, the abscissas indicated the degree of familiarity with arbitrary intervals, and experimental data mentioned above were plotted. The curves were simply extended from the maximum familiasity to the complete unknown. Similary, in the right two figures the degree of intralist similarity was taken on the abscissas, but their extended curves were complex. If $S$ items in a list were very much similar one another theycould hardly be discriminated, and if all $\mathrm{S}$ items were apparently identical, ( $R$ items may be of any degree of similarity except identity) such a list could not be learned over chance level. Thus, the number of trials to mastery is infinitely great. On the other hand, when $\mathrm{R}$ item sin a list are maximally similar, namely, apparently identical ( $\mathrm{S}$ items may be 
of any degree of similarity), the subject may use an identical $\mathbf{R}$ to all $\mathrm{S}$ items. Then, the number of trials to mastery is very few. Based on these figures, Fig.6 was drawn to present two three-dimensional surfaces showing the relation ships between the rate $o$ paired-associate learning and materials to be learned. Fig. 6
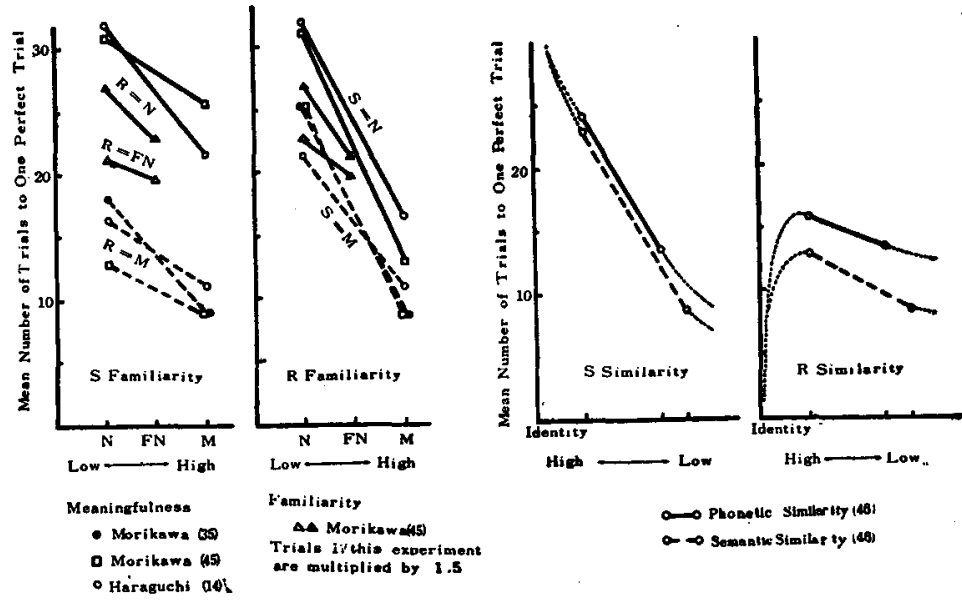

Fig. 5 Mean number of trials to one perfect trial as a functions of familiarity and intralist similarity of $S$ and $R$

suggests that similarity dimension of material is very much different from familiarity dimension with respect to the rate of pairedassociate learning. The former agrees with Gibson's view, and the latter with Kuraishi's.

II. Functions of Stimulus and Response in Paired-Associate Learning 1. Forward-backward recall gradient (FB-RclG) and forward-backward recognition gradient (FB-RcgG)

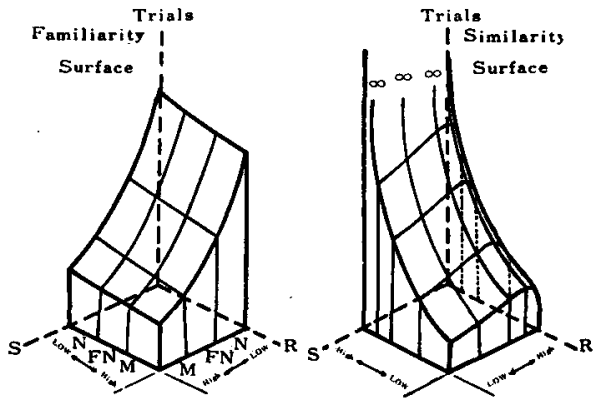

Fig. 6 S-R-trials surfaces

Winzen (81) first studied on the comparison between forward recall $(S \rightarrow R)$ and backward recall $(\mathrm{R} \rightarrow \mathrm{S})$ after several paired-presentations of learning material. The study was followed by Stoddard (66), Guthrie (13), Kuraishi (27), Umemoto (71), Morikawa (35, 36, 37, 38, 40, 44, 45, 46), Feldman \& Underwood (7) and Jantz \& Underwood (18).* All the studies but Guthrie's, found that forward recall was better than backward recall. Morikawa (35) defined 'forward-backward recall gradient' (FB-RclG) as the difference between forward recall and backward recall, and defined 'forward-backward recognition gradient' (FB-RcgG) as the difference between forward recognition and backward recognition, after paired-associate learning. ${ }^{\star \star}$ In that study, some variables concerning FB-RclG were investigated, and the results were summarized as follows:

* In the present paper, no statements have been made about the effect of backward learning in transfer, although the studies $(15,17,44,47,48)$ are closely related to the problem discussed here.

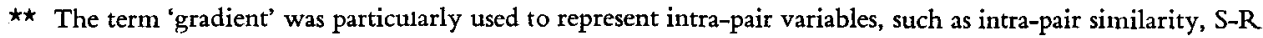
homogeneity, S-R compatibility, S-R time interval, etc. But, in this paper, we did not refer to intra-pair relationships, because in all experiments quoted the intra-pair variable was not investigated. So, the following figures were drawn with S-R distance kept constant. FB-RclG was computed by substracting the number of items backward recalled $(R \rightarrow S)$ from the number of items forward recalled $(S \rightarrow R)$. 
1) When the degree of forward learning was equal, FB-RclG was a function of the kind of $S$ materials. The less familiar the $\mathrm{S}$ items were, the more was FB-RclG.

2) FB-RclG was a function of the degree of forward learning. FB-RclG increased gradually in the early stage of learning, and reached its maximum in the middle stage, and then decreased when overlearned.

3) When a list was overlearned, FB-RclG was correlated to list length. The longer the list length became, the more FB-RclG was.

4) FB-RclG was a function of methods of paired-presentation. FB-RclG was greater after a list was learned by the paired-anticipation method than by the simultaneous paired-presentation.

5) When backward tests were repeatedly interpolated in the course of learning, FB-RclG tended to decrease.

6) FB-RclG was greater for the naive subject than for the experienced.

7) FB-RclG was independent of the rate of presentation in learning and testing, when the simultaneous presentation method was used.

8) Mean latency times for forward recall were shorter than those for backward recall.

The following hypotheses were suggested in order to explain the obtained FB-RclG: 1) hypothesis of $S$ discrimination and $R$ item-acquisition learning, 2) hypothesis that $S$ item is acquired incidentally, 3) hypothesis of temporal directional association.

2. $S$ 'discrinination' and $R$ 'item-acquisition' hypothesis

It goes without saying that in paired-associate learning the subject's task is to answer a correct $R$ assigned for a given $S$. Then, he need not perfectly remember $S$ item, because $S$ is only a sign or cue to the corresponding $\mathrm{R}$. While, $\mathrm{R}$ must be responded to on every trial. In other words, $\mathrm{S}$ item is learned only discriminatingly as a cue for $\mathrm{R}$, but $\mathrm{R}$ item is learned acquiringly as the actual goal to be responded to. The fact that backward recall was inferior to forward recall supports this hypothesis.

The same hypothesis leads to the following predictions: 1) When forward learning level is identical, backward recall of highly similar intra-S lists should be better than that of dissimilar intra-S lists, because subjects who learned similar lists had to differentiate more discriminating cues, so that the similar S items may be learned up to the level of item-acquisition. 2) If recognition test which need not require perfect recall was used, backward association should not differ from forward association, i.e., FB-RcgG should decrease to zero. 3) If free recall test is utilized in which subjects are instructed to write down as many items as they can remember, regardless of the pair of learned lists, free recall of $R$ items should be better than that of $S$ items. The difference between $R$ free recall and $S$ free recall should be paralleled to FB-RclG, when lists are low similar. In the following paragraphs some attempt will be made to verify the above predictions based on the empirical data.

In two experiments on similarity (46) mentioned above, the subject was presented orally $\mathrm{S}$ or $\mathrm{R}$ at a $10-\mathrm{sec}$. rate, immediately after attaining the criteria, and was asked to recall the other item which went with $\mathrm{S}$ or $\mathrm{R}$. The criteria of recall testing were three levels of learning: about $1 / 2$ correct responses on a single trial, one perfect trial and 3 successive perfect trials. As shown in Fig.7 the results confirmed prediction 1. In nonsense syllable lists, FB-RclG in H-L lists was always smaller than those in lists, L-H and L-L. The latter were statistically significant on all testing criteria, but backward recall of $\mathrm{H}-\mathrm{L}$ lists did not significantly differ from forward recall except after one perfect trial. * In meaningful (adjectives) lists, all FB-

* But these results concerning backward recall did not agree with the results of Feldman \& Underwood (7), in which they found that the amount of backward recall was independent of intralist similarity. Such disagreement may be due to the difference of the degree of similarity or the method of testing used in both studies. 
RclGs were insignificant, so meaningful pair conditions could not be used to test this: prediction.

Another experiment (42)was designed to examine the second prediction. Lists consisting of either 5 pairs of $\mathrm{N}-\mathrm{N}$ or 6 pairs of $\mathrm{N}-\mathrm{M}$, (the non-association val:es of $\mathrm{M}$ items were $0-4$, those of $\mathrm{N}$ items were $50-55$ (74)) which both yielded the maximum FB-RclG in a previous study (35), were presented to the subject 6 times by paired-anticipation method ( $3 \mathrm{sec}$. for $S$, and $3 \mathrm{sec}$. for S-R). Immediately after the sixth trial, one group was tested by the right associate recall method, the other group by the paired-reconstruction method, both from $S$ and $R$. The results, as shown in Fig. 8, indicated that FB-RcgG was much less than FB-RclG in both lists.

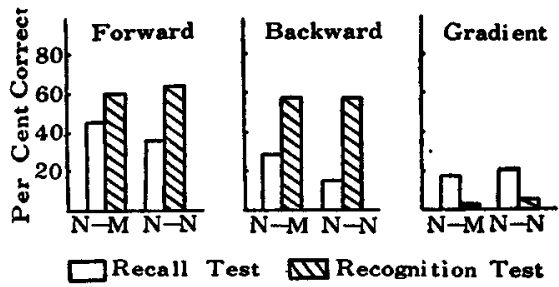

Fig. 8 Forward, back ward recall or recognition, and FB-RclG and FB-RcgG (42).

This might be interpreted to support prediction 2 .

In order to examine prediction 3, right associate recall was compared with free recall after paired-associate learning (44). Immediately after a list of 5 pairs of $\mathrm{N}-\mathrm{N}$ was given 6 times at a rate of $5 \mathrm{sec}$, by the simultaneous presentation of $S-R$, right associate recall test was performed both from $S$ and $R$, and then free recall test

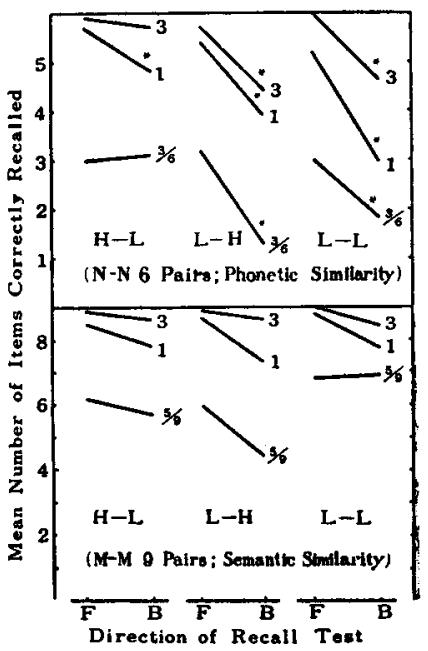

F: Forward recall,

B: Backward recall,

Lines show FB-RclG.

* Stared FB-RclGs are

significant beyond the .05 level.

3/6: Test after 3 out of 6 correct

trial,

5/9: Test after 5 out of 9 correct trial,

1: Test after one errorless trial,

3: Test after three successive errorless trials.

Fig. 7 Forward and backward recall and $\mathrm{FB}-\mathrm{RclG}$ as a function of intralist similarity and degree of learning (46).

was followed. As shown in Fig. 9, the results of two tests were highly similar. This finding may be deduced from the prediction.

\section{S item is acquired incidentally}

In any of the writer's experiments the subject was not informed that backward test is. performed. In all experiments except 4 experiments $(45,46)$ cited earlier, subjects (junior high school students) were no experience to verbal experiments, and they were used only one condition. When the subject served in experiments, he was emphasized to learn as fast as. possible in paired-anticipation learning without regard to the performance of recall test. Nevertheless, the fact that the subject could recall correctly some $S$ items when backward recall test or free recall test was given, suggests that $\mathrm{S}$ items may by incidentally acquired. during paired-associate learning. If $S$ items were learned incidentally, it should be expected. 
that functions which influence upon incidental learning would be comparable with those of backward recall. Morikawa $(37,42)$

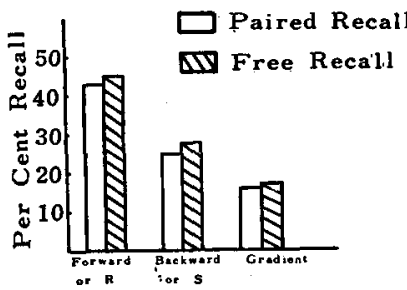
reviewed, in detail, comparisons between incidental and

Fig. 9 Percentage of pairedassociate recall and free recall after 6 presentations of pairednonsense syllables (44).

backward learning, and he concluded that $\mathrm{S}$ items in paired-associate lists may be acquired incidentally in the course of paired-associate learning. Feldman \& Underwood (7) and Jantz \& Underwood(18)also suggested that backward learning might be a form of incidental learning.

Now, the data of $S$ learning or backward testing will be compared with the data in incidental learning, with respect to meaningfulness, method of testing, intralist similarity, degree of learning, and isolation effect.

1) Meaningfulness and method of testing The data concerning relationships of meaningfulness and incidental learning showed that the difference between incidental and intentional learning was great when $\mathrm{N}$ lists were used and the performance was measured by recall test $(2,25,57,59,60)$, and the difference was a little or none when either $M$ or $N$ lists were tested by recognition method $(20,59,60)$ with an exception of Karen's $M$ list. But the results were conflicting when $M$ lists were tested by recall method $(2,25,59,60)$.

In the two experiments on meaningfulness and familiarity (45) mentioned above, the writer investigated FB-RclG after three degrees of learning by the same procedures as in the experiments on similarity (46). These results are presented in Fig.10. As can be seen, FB-RclG and backward recall were a function of familiarity or meaningfulness of $S$ niaterials. Backward recall was smaller when $S$ was unfamiliar or meaningless than when $S$ was familiarized or meaningful. FB-RclG did not appear for M-M lists. The result coincided with the finding in incidental experiments, though two recall test methods differ to some extent, i.e., the one is paired-associate test, the other free recall test. Backward recognition in $\mathrm{N}-\mathrm{N}$ lists did not differ from forward recognition. This result was also somewhat similar to that in incidental learning, though the two recognition test methods used were different.

2) Intralist sinilarity Furthermore, incidental and backward learning showed a high correspondence to each other concerning intralist similarity. The decrease in FB-RclG as a function of intralist S similarity (46) (see Fig. 7) paralleled the decrease of the difference between intentional and incidental learning as a function of intralist similarity $(25,58)$.

3) Degree of learning Another evidence was given from the data concerning the degree of learning. Bahrick (1) found that the rate of incidental learning was fast in early learning. 
stage, then became slow in middle stage, and again fast when intentionally learned list was overlearned. Other studies (35 Exp. II, 80) that investigated backward recall as a function of the degree of forward learning (including overlearning), found parallel results to those of incidental learning. A number of studies $(12,26,64)$ showed that, the more the number of presentations of a list was, the greater was the difference between incidental and intentional learning, when the final learning level was relatively low, and these results also agreed with those of FB-RclG $(18,35)$.

4) Isolation effect A further evidence of this hypothesis was found in studies on the isolation effect. Several works $(12,23,24,61)$ which investigated the isolation effect in incidental learning found that (a) in the relative isolation design (using color or other perceptual cues) facilitating effect of isolation is little both in incidental and in intentional learning when number of presentations is few, that (b) in the relative isolation design using the variation in materials (Siegel type) the effect appears only in intentional learning, that (c) with respect to the absolute isolation by the use of differences in material (von Restorff type) facilitation occurs in both learning condi ions. Therefore, if backward learning is a form of incidental learning, the above mentioned isolation conditions in $S$ items of paired-lists may yield similar results to the incidental data.

Now, we will present the experimental data which examine this expectation (44). Each of the lists which consisted of 5 pairs of $\mathrm{N}-\mathrm{N}$ or two alphabets in nonsense combinations was given visually at a rate of $5 \mathrm{sec}$., 6 times by the simultaneous S-R presentation method, and then forward and backward recall tests were performed. Conditions of isolation were color (red item within black items) and material (alphabet within Ns, or $\mathrm{N}$ within alphabets), and the isolated item spaced in $\mathrm{S}$ side, $\mathrm{R}$ side, or $\mathrm{S}-\mathrm{R}$ pair. The results, as shown in Fig.11, corresponded with incidental learning results: namely, on backward recall facilitation was the greatest with isolation by material, and little with isolation by color. In other experiments (44) isolation effects were studied using high similarity lists. It was found that facilitation was greater when $\mathrm{S}$ was isolated than when $\mathrm{R}$ was isolated. This finding may be used to support the hypothesis that $\mathrm{S}$ is mainly learned discriminatingly.

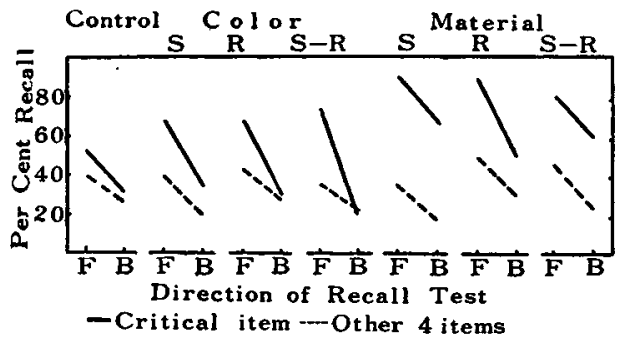

Fig. 11 Percentage of forward, backward recall and FB-RclG as a function of isolation of $S$ and/or $\mathrm{R}$ (44).

\section{Termporal factor in association}

It is a well-known fact that in conditioning the time interval between CS and UCS or between $\mathrm{S}$ and $\mathrm{R}$ is an important factor in formation of association. Especially, when UCS proceeds CS (backward conditioning), learning is very difficult or impossible. Backward association in verbal learning, however, is quite distinct from backward conditioning in material and in procedures (13). Backward association has been found on serial rote learning from the time of Ebbinghaus (6). The fact that backward association is weaker than forward association was used to account for serial position effects in rote-learning (32). Thorndike (69) called an 
unsymmetry of association based upon temporal sequence, as 'polarity' effects.

In the previous sections, inferiority of backward recall was discussed in terms of the characteristics of paired-anticipation method in which learning of $S$ items differed from that of $R$ items. Now the temporal factor in paired-association will be considered. In Morikawa's first report (35, Exp. IVa-Vb), lists were learned by the simultaneous paired-presentation which did not require to anticipate $\mathrm{R}$ items. * Again, forward recall was superior to backward recall, although here the superiority was smaller than when the anticipation method was used. Furthermore, insignificant but positive gradients were found by the recognition test in the second study (42). These results may support the importance of temporal factor. Of course, the temporal factor is not the only factor in a complex phenomenon of paired-associate learning, but such factor as previously considered must be taken in account as well.

Consideration of the temporal factor lead to an investigation of the influence of time intervals on FB-RclG. In 1955 Morikawa (36) reported experiments in which FB-RclG was found as a function of time intervals between learning and testing. Four experimental groups were given a recall test from forward and backward directions $20 \mathrm{sec}$., $30 \mathrm{~min}$., 24 hrs. or 7 days after 6 presentations of a list of $6 \mathrm{~N}-\mathrm{M}$ pairs. The four groups were divided into two sub-groups (who were assigned different list sets) of about 45 junior high school students (13-15 years old) each. The subjects were all naive and were not informed of the retention test. Each group was tested immediately after learning (learning score), and then was retested after different time intervals (retention score). Fig.12 presents retention curves for forward and backward recall, and FB-RclG. Scores were adjusted based on learning score. It is notice that backward recall after $30 \mathrm{~min}$. is better than after $20 \mathrm{sec}$. at the $5 \%$ level of confidence ( $t$-test). In another experiment this reminiscence in backward recall was also obtained on the test $5 \mathrm{~min}$. after learning N-N lists of 6 pairs to a $4 / 6$ correct criterion with 9

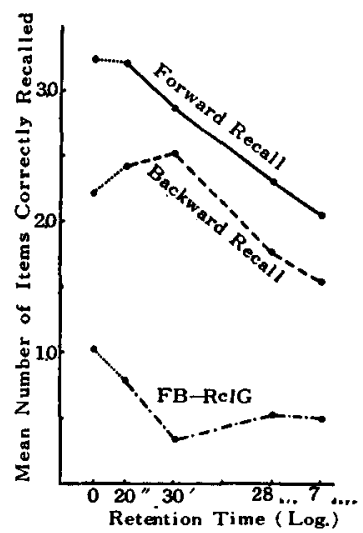

Fig. 12 Retention curves as a function of the time interval after learning $\mathrm{N}-\mathrm{M}$ list (36). university students served as subjects. But, when $\mathrm{M}-\mathrm{N}$ lists were used, reminiscence in backward recall did not appear.

We interprete the phenomenon as facilitation of backward recall by spontaneous recovery from temporal associative inhibition (which may be similar to reactive inhibition). The inhibition is probably produced by a transiently temporal factor or a set of motor patterning in the direction from $\mathrm{S}$ to $\mathrm{R}$. Varidity of this factor was confirmed in the writer's two studies on the distribution of practice (38) and by the use of the modified free recall test (40).

\section{Process of paired-associate learning.}

In order to summarize the previous discussions, Fig.13 presents the relations among the variables, the constructs, and the measures. The solid lines indicate the primary relations among the terms, and the broken lines the incidental or secondary relations.

\footnotetext{
* In this case the left member of a pair was defined as $S$, and the right member as $\mathrm{R}$, according to the cust mary usage in verbal learning experiments.
} 


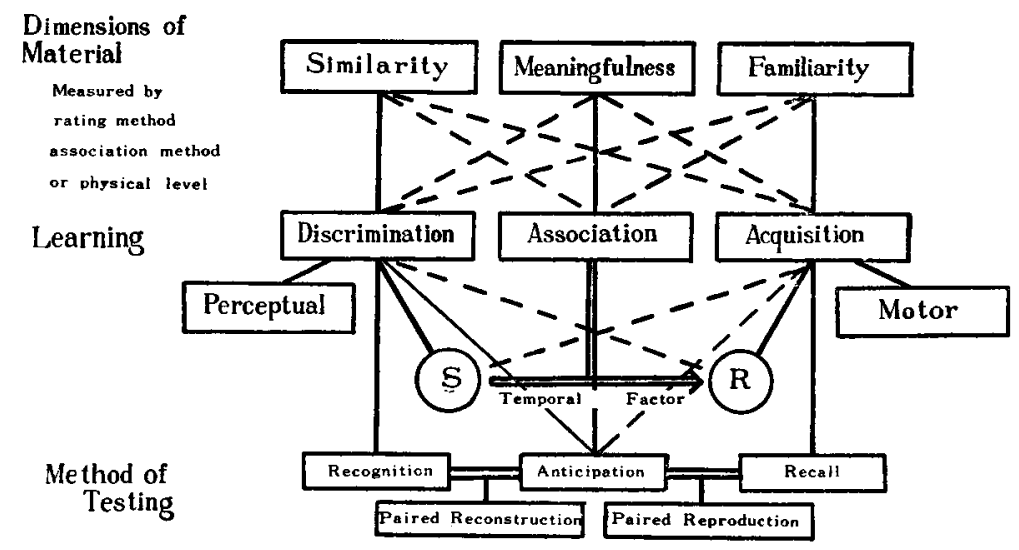

Fig. 13 Summary of the relations among the variables, the constructs and the measures in paired-associate verbal learning.

We consider that in paired-associate learning by anticipation method the following three kinds of learning proceed concurrently.

1) Stimulus discrimination When a paired-associate list is learned by anticipation method, generalization among $S$ items will increase to a maximum during the early stage of practice, after which discrimination will be established as practice is continued. ${ }^{\star}$ This view corresponds to Gibson's stimulus differentiation theory (9), and this learning process may be related to the perceptual learning (11). Learning of $S$ items in paired-associates is establishment of discrimination among items. The item-acquisition of $S$ is not necessary, but $S$ may be incidentally acquired as a function of the degree of practice. The $\mathrm{S}$ item-acquisition, however, is never an indispensable condition for completion of paired-associate learning.

2) $R$ item-acquisition $\mathrm{R}$ items in a list have not only to be differentiated in connection with a particular $S$, but also to be responded overtly with utilizing effector organs. Here, itemacquisition means that the item is remembered and can be recalled spontaneously, and not that it can be recognized or reconstructed. In verbal learning each item is composed of phonetical sign (letter) units, whose unusual combinations are called $\mathrm{N}$, and whose conventional sequences $M$. As the unit itself is already acquired very well, integration of these units may be called item-acquisition in $\mathrm{N}$ items. When the items to be learned are $\mathrm{M}$ or $\mathrm{FN}$, it may be necessary only to determining what items are involved in a list, but item-acquisition not necessary. This conception of item-acquisition is closely related to Mandler's concept of response integration (29).

3) Reinforcement of $S \rightarrow R$ paired-association As a paired-associate list is repeatedly presented, particular $R$ items will be correctly answered to their assigning $S$ items. The overt correct anticipation, however, should not appear until item-acquisition of $\mathrm{R}$ is attained, while, even if $\mathrm{R}$ is acquired, the correct anticipation should not appear until discrimination of $\mathrm{S}$ is attained. In the early stage of learning in which stimulus generalization develops,

* Such increasing generalization in the middle stage of practice may be brought (at least, in part) about by way of the increasing item-acquitision of $R$ as mentioned in next paragraph. 
apparently random paired anticipation may occur between generalized $S$ items and some $R$ items that have already completed item-acquisition. ${ }^{\star}$ As $\mathrm{S}$ discrimination proceeds, however, correct association between specific $S$ and $R$ is strengthened, and incorrect association is weakened as the results of differential inhibition. Then, fixed association involving vector from $\mathrm{S}$ to $\mathrm{R}$ is established, and finally association of all pairs in a list is completed. Indeed, this process may be considered the essential part of paired-associate learning.

Fig.14 shows an ideal model of the development of these learning processes in which the relative rate and the weight may be varied according to the various variables. It is summarized as follows.

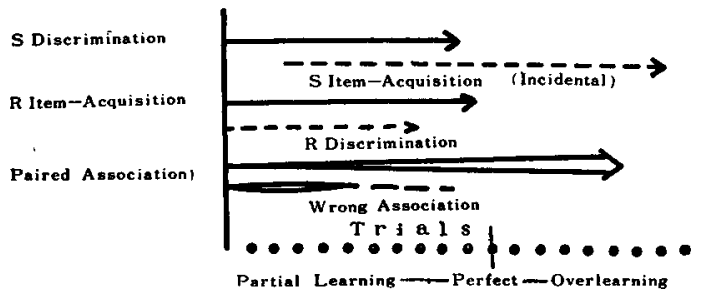

Fig. 14 A model illustrating process of paired-associate learning by anticipation method.

A hypothesis concerning the process of paired-associate learning by anticipation method In paired associate learning by anticipation method, subjects may learn, concurrently, to discriminate $S$ items, to acquire $R$ items, and to pair $\mathrm{S}$ and assigned $\mathrm{R}$ in a list. When all of these processes of learning are finished, pairedassociation is apparently completed.

The present theoretical framework may be applied to some of empirical results that have been obtained in studies of interlist relationships, such as transfer, retroaction and mediated association. Furthermore, a resolution of similarity paradox may be suggested from S-Rtrials surface on similarity in Fig.6 $(39,41,43)$.

\section{SUMMARY}

First, it was asserted that in paired-associate learning variation of intralist similarity is effective in $\mathrm{S}$ items of paired-lists, but that familiarity is more important factor in $\mathrm{R}$ items. It was suggested that meaningfulness is mainly related to the strength of S-R connection, though its effect is somewhat similar to the effect of familiarity. Two surfaces in Fig. 6 summarized our argument, based on empirical data and theoretical considerations, and showed the relationships between the difficulty of learning and material dimensions (familiarity and similarity).

Second, an attempt was made to examine functions of $S$ and $R$ in paired-associate verbal learning, based on experimental evidence on backward (R-S) learning. Backward learning was investigated with reference to variables of meaningfulness, familiarity, intralist similarity, isolation, degree of learning, methods of learning, methods of testing, and learning-testing time intervals. Several lines of evidence reviewed supported the hypothesis that $S$ items are mainly learned through discrimination, and are incidentally acquired, and that $R$ items are intentionally acquired.

\section{REFERENCES}

1. Bahrick, H. P. Incidental learning at five stages of intentional learning. J. exp. Psychol., 1957, 54, 259-261.

2. Brown, G. H. Factors influencing incidental learning. J. exp. Psychol., 1954, 47, 163-169.

3. Calkins, M. W. D. Association I. Psychol. Rev., 1894, 1, 476-483.

4. Calkins, M. W. D. Association: An essay analytic and experimental. Psychol. Monogr., 1896, 1, No.2.

5. Cleutat, V. J., Stockwell, F. E., \& Noble, C. E. The interaction of ability and amount of practice with

* This statement is followed from the finding that subjects who learned lists in which $\mathrm{R}$ consisted of either $\mathrm{M}$ or FN, produced more overt intralist intrusion crrors, than those subjects who learned lists in which $\mathrm{R}$ consisted of $\mathrm{N}$. 
stimulus and response meaningfulness $\left(\mathrm{m}, \mathrm{m}^{\prime}\right)$ in paired-associate learning. $J$. exp. Psychol., 1958, 56, 193-202.

6. Ebbinghaus, H. Über das Gedächtnis: Untersuchungen zur experimentellen Psychologie. Leipzig: Duncker \& Humblot, 1885.

7. Feldman, S. M., \& Underwood, B. J. Stimulus recall following paired-associate verbal learning. J. exp. Psychol., 1957, 53, 11-15.

8. Gagné, R. M., \& Baker, K. E. Stimulus pre-differentiation as a factor in transfer of training. J. exp. Psychol., 1950, 40, 439-451.

9. Gibson, E. J. A systematic application of the concepts of generalization and differentiation to verbal learning. Psychol. Rev., 1940, 47, 196-229.

10. Gibson, E. J. Intra-list generalization as a factor in verbal learning. J. exp. Psychol., 1942, 30, 185-201.

11. Gibson, J. J., \& Gibson, E. J. Perceptual learning: Differentiation or enrichment? Psychol. Rev., 1955, 62, 32-41.

12. Gleitman, H., \& Gillett, E. The effect of intention upon learning. J.gen. Psychol., 1957, 57, $137-149$.

13. Guthrie, E. R. Association as a function of time interval. Psychol. Rev., 1933, 40, 355-367.

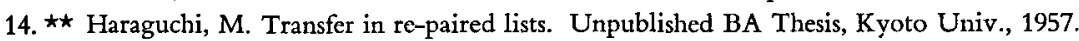

15. Harcum, E. R. Verbal transfer of overlearned forward and backward associations. Amer. J. Psychol. 1953, 66, 622-625.

16. Hovland, C. I., \& Kurtz, K. H. Experimental studies in rote-learning theory: X. Prelearning syllablefamiliarization and the length-difficulty relationship. J. exp. Psychol., 1952, 44, 31-39.

17. $\star \star$ Ibuki, M. On memory: The role of stimulus and response in transfer and proaction. Unpublished BA Thesis, Kyoto Univ., 1954.

18. Jantz, E. M., \& Underwood, B. J. R-S learning as a function of meaningfulness and degree of S-R learning. J. exp. Psychol., 1958, 56, 174-179.

19. Jost, A. Die Assoziationsfestigkeit in ihrer Abhängigkeit von der Verteilung der Wiederholungen. Z. Psychol., 1897, 14, 436-472.

20. Karen, R. L. Recognition as a function of meaningfulness and intention to learn. Amer. J. Psychol., $1956,69,650-652$.

21. Kimble, G. A., \& Dufort, R. H. Meaningfulness and isolation as factors in verbal learning. J. exp. Psychol., 1955, 50, 361-368.

22. Köhler, W. On the nature of associations. Symposium on recent advantage in psychology, 1941.

23. * Koyanagi, K. Studies in incidental learning: I. Intention of learning and isolation-effect. Jap. J. Psychol., 1957, 27, 270-278.

24. Koyanagi, K. Studies in incidental learning: II. Intraserial interference. Tohoku Psychol. Folia, 1957, 15, Fasc. 3-4, 1-11.

25. $\star \star$ Koyanagi, K. Studies in incidental learning: III. Clustering response and association response. Bunka, 1957, 21, 172-182.

26. * Koyanagi, K. Studies in incidental learning: VI. The effect of rate and number of stimulus-presentation. Jap.J. educ. Psychol., 1958, 6, 100-105.

27. * Kuraishi, S. On the reproduction of simple thought-configuration by using the method of paired comparison. Jap. J. Psychol., 1937, 12, 578-602.

28. Lepley, W. M. An hypothesis concerning the generation and use of synonyms. J. exp. Psychol., 1950, 40. 527-530.

29. Mandler, G. Response factors in human learning. Psychol. Rev., 1954, 61, 235-244.

30. Mandler, G. \& Campbell, E.H. Effect of variation in associative frequency of stimulus and response members on paired-associate learning. J. exp. Psychol., 1957, 54, 269-273.

31. Mandler, G., \& Huttenlocher, J. The relationship between associative frequency, associative ability and paired-associate learning. Amer. J. Psychol., 1956, 69, 424-428.

32. McGeoch, J. A., \& Irion, A. L. Psychology of human learning. New York; Longmans, 1952.

33. McGeoch, J. A., \& McGeoch, G. O. Studies in retroactive inhibition: X. The influence of similarity of meaning between lists of paired associates. J. exp. Psychol., 1937, 21, 320-329.

34. Morgan, R. L., \& Underwood, B. J. Proactive inhibition as a function of response similarity. J. exp. Psychol., 1950, 40, 592-603. 
35. * Morikawa, Y. Studies in paired-associate learning: I. Forward-backward recall gradient. Jap. J. Psychol., 1955, 26, 156-171.

36. * Morikawa, Y. Forward-backward recall gradient as a function of retention time. Rep. 57. Conven. Midwest. Jap. Psychol. Ass., 1955.

37. ** Morikawa, Y. Studies in paired-associate learning. Unpublished MA Thesis, Kyoto Univ., 1956.

38. ** Morikawa, Y. Forward-backward recall gradient as a function of distribution of practice. Rep. 58, Conven. Midwest. Jap. Psychol. Ass., 1956.

39. *ᄎ Morikawa, Y. Similarity paradox as both functions of discrimination and acquisition. Rep. 59. Conven. Midwest. Jap. Psychol. Ass., 1956.

40. $\star$ Morikawa, Y. A study of forward-backward recall gradient by the use of MFR. Rep. 21. Conven. JPA. 1957.

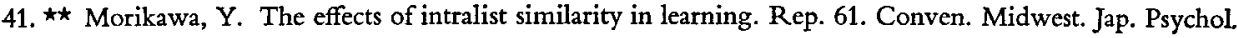
Ass., 1957.

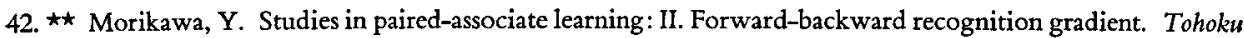
J. exp. Psychol., 1958, 2, 57-62.

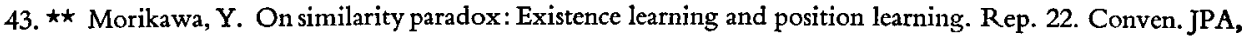
1958.

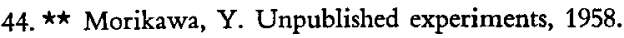

45. * Morikawa, Y. Studies in paired-associate learning: III. The influence of meaningfulness and familiarity of stimulus and response on learning and recall. Jap. J. Psychol., 1959, 30, (in press)

46* Morikawa, Y. Studies in paired-associate learning: IV. The influence of intralist similarity of stimulus and response on learning and recall. Jap. J. Psychol. (in preparation)

47. Murdock, B. B., Jr. "Backward" learning in paired associates. J. exp. Psychol., 1956, 51, $213-215$.

48. Murdock, B. B., Jr. "Backward” associations in transfer and learning. J. exp. Psychol., 1958, 55, 111-114.

49. $\star \star$ Nemoto, $N$. On the influence of system of material upon learning. Unpublished BA Thesis, Kyoto Univ., 1957.

50. Noble, C. E. The meaning-familiarity relationship. Psychol. Rev., 1953, 60, 89-98.

51. Noble, C. E. The familiarity-frequency relationship. J. exp. Psychol, , 1954, 47, 13-16.

52. Noble, C. E. The effect of familiarization upon serial verbal learning. J. exp. Psychol., 1955, 49, 333-338.

53. Noble, C. E., \& McNeely, D. A. The role of meaningfulness (m) in paired-associate verbal learning. $J$. exp. Psychol., 1957, 53, 16-22.

54. Osgood, C. E. Meaning similarity and interference in learning. J. exp. Psychol., 1946, 36, 277-301.

55. Osgood, C. E. An investigation into the cause of retroactive interference. J. exp. Psychol., 1948, 38, 132-154.

56. Postman, L. Learned principle of organization in memory. Psychol. Monogr., 1954, 68, No.3 (Whole No.374).

57. Postman, L., \& Adams, P. A. Studies in incidental learning: IV. The interaction of orienting tasks and stimulus materials. J. exp. Psychol., 1956, 51, 329-333.

58. Postman, L., \& Adams, P. A. Studies in incidental learning: VI. Intraserial interference. J. exp. Psychol., 1957, 54, 153-167.

59. Postman, L., Adams, P. A., \& Bohm, A. M. Studies in incidental learning: V. Recall for order and associative clustering. J. exp. Psychol., 1956, 51, 334-342.

60. Postman, L., Adams, P. A., \& Phillips, L. W. Studies in incidental learning: II. The effects of association value and of the method of testing. J. exp. Psychol., 1955, 49,1-10.

61. Postman, L., \& Phillips, L. W. Studies in incidental learning: I. The effects of crowding and isolation. J. exp. Psychol., 1954, 48, 48-56.

62. Postman, L., \& Riley, D. A. A critique of Kohler's theory of association. Psychol. Rev., 1957, 64, 61-72.

63. * Sagara, M. Recall of items in paired associates. Jap. J. Psychol., 1939, 14, 89-96.

64. Saltzman, I. J., \& Atkinson, R. L. Comparisons of incidental and intentional learning after different numbers of stimulus presentation. J. Psychol., 1954, 67, 521-524.

65. Sheffield, F. D. The role of meaningfulness of stimulus and response in verbal learning. Unpublished Ph. D. dissertation, Yale Univer., 1946. 
66. Stoddard, G. D. An experiment in verbal learning. J. educ. Psychol., 1929, 20, 452-457.

67. Thorndike. E. L. A note on assimilation and interference. Amer. J. Psychol., 1937, 49. 671-676.

68. Thorndike, E. L. On the frequency of semantic changes in modern English. J. gen. Psychol., 1948, 39, 23-27.

69. Thorndike, E. L., et al. The fundamentals of learning. New York: Teachers College, Columbia Univ., 1932.

70. * Umemoto, T. Association values of 1016 Japanese nonsense syllables. Jap. J. Psychol., 1951, 21, $23-28$.

71. * Umemoto, T. The relative weight of stimulus versus response words in rote learning. Jap. J. Psychol., $1951,21,46-55$.

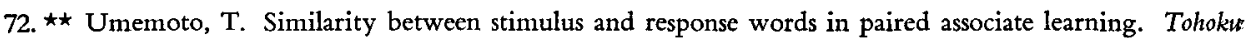
J. exp. Psychol., 1958, 2, 95-102.

73. Umemoto, T. Japanese studies in verbal learning and memory. Psychologia, 1959, 2,1-19.

74. * Umemoto, T., Morikawa, Y., \& Ibuki, M. The non-association values and meaningfulness of 1892 Japanese two-letter syllables and words. Jap. J. Psychol., 1955, 26, 148-155.

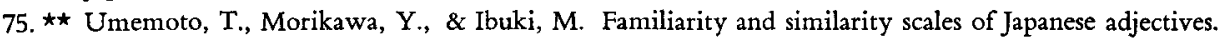
Kyoto Univ. Res. Studies in Educ., 1955, 1, 85-116.

76. Underwood, B. J. Experimental psychology. New York: Appleton-Century-Crofts, 1949.

77. Underwood, B. J. Studies of distributed practice: II. Learning and retention of paired-adjective lists with two levels of intra-list similarity. J. exp. Psychol., 1951, 42, 153-161.

78. Underwood, B. J. Studies of distributed practice: VIII. Learning and retention of paired nonsense syllables as a function of intralist similarity. J. exp. Psychol., 1953, 45, 133-142.

79. Underwood, B. J. Studies of distributed practice: IX. Learning and retention of paired adjectives as a function of intralist similarity. J. exp. Psychol., 1953, 45, 143-149.

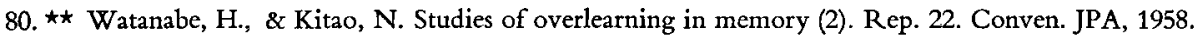

81. Winzen, K. Die Abhangigkeit der paarweisen Assoziation von der Stellung des besser haftenden Gliedes. Z. Psychol., 1921, 86, 236-252.

82. Young, R, K., Retroactive and proactive effects under varying conditions of response similarity. $J$. exp. Psychol., 1955, 50, 113-119.

83. Young, R. K., \& Underwood, B. J. Transfer in verbal materials with dissimilar stimuli and responsesimilarity varied. J. exp. Psychol., 1954, 47, 153-159.

84. Zipf, G. K. The meaning-frequency relationship of words. J. gen. Psychol, 1945, 33, 251-256.

* Written in Japanese with English summary.

$\star \star \quad$ Written in Japanese.

MS. received II 12, 59.

Yasuo Morikawa（森门弥寿雄, 1929- ), B.A., 1954; M.A., 1956; 1956- , doctor candidate, Department: of Psychology, Kyoto Univ. 